\title{
Atrial Natriuretic Peptide Modulates Synaptic Transmission from Osmoreceptor Afferents to the Supraoptic Nucleus
}

\author{
Dominique Richard and Charles W. Bourque \\ Centre for Research in Neuroscience, Montreal General Hospital Research Institute and McGill University, Montréal, \\ Québec, Canada H3G 1A4
}

Atrial natriuretic peptide (ANP) and its receptors are present in hypothalamic nuclei containing the magnocellular neurosecretory cells (MNCs), which release vasopressin and oxytocin. In the rat, intracerebroventricular injections of ANP inhibit the release of both hormones in response to hypertonicity. Although these findings suggest a role for endogenous ANP in the central control of fluid balance, cellular mechanisms underlying the modulatory actions of ANP are unknown. We therefore examined the effects of ANP on the osmoresponsiveness of MNCs impaled in rat hypothalamic explants. Applications of ANP (75-150 nM) over the supraoptic nucleus did not affect depolarizing responses to local hypertonicity, but they reversibly abolished the synaptic excitation of MNCs after hypertonic stimulation of the organum vasculosum laminae terminalis (OVLT). These effects were associated with decreased spontaneous EPSP (sEPSP) amplitude rather than with changes in sEPSP frequency. Accordingly, application of ANP reduced the amplitude of glutamatergic EPSPs evoked by electrical stimulation of the OVLT $\left(\mathrm{IC}_{50} \sim 3 \mathrm{~nm}\right)$. The inhibitory effects of ANP on EPSP amplitude were mimicked by application of $3^{\prime}-5^{\prime}-$ dibutyryl cGMP, consistent with the guanylate cyclase activity of natriuretic peptide receptors. Although depolarizing responses of MNCs to ionotropic glutamate receptor agonists were unaffected by ANP, the peptide reversibly enhanced paired-pulse facilitation of electrically evoked EPSPs. These results indicate that centrally released ANP may inhibit osmotically evoked neurohypophysial hormone release through presynaptic inhibition of glutamate release from osmoreceptor afferents derived from the OVLT.

Key words: atrial natriuretic peptide; supraoptic nucleus; OVLT; organum vasculosum lamina terminalis; osmoregulation; vasopressin; oxytocin; osmoreceptor; presynaptic inhibition
Atrial natriuretic peptide (ANP) is a 28 amino acid hormone that was first identified in heart myocytes (deBold, 1985). Systemic release of ANP by the atria, which follows expansion of extracellular fluid volume (Lang et al., 1985; Eskay et al., 1986), promotes relaxation of the vascular smooth muscle as well as diuresis and natriuresis at the level of the kidneys (Brenner et al., 1990). Circulating ANP, therefore, plays an important role in cardiovascular and body fluid homeostasis. Natriuretic peptides including ANP and brain natriuretic peptide (BNP) have also been detected in the CNS (Imura et al., 1992). These peptides (Saper et al., 1985, 1989; Standaert et al., 1986) and their receptors (Gibson et al., 1986) are particularly abundant in CNS regions that participate in the autonomic and neuroendocrine regulation of blood pressure and fluid balance. Moreover, intracerebroventricular injections of ANP interfere with hypertonically evoked changes in thirst (Antunes-Rodriguez et al., 1985; Nakamura et al., 1985; Katsuura et al., 1986), salt appetite (Fitts et al., 1985; Antunes-Rodriguez et al., 1986), and diuresis (Itake et al., 1986; Poole et al., 1987; Samson et al., 1987; Manzanares et al., 1990). Although these observations suggest a role for centrally released ANP in the

Received Aug. 25, 1996; revised Sept. 17, 1996; accepted Sept. 18, 1996.

This work was supported by an operating grant from the Medical Research Council (MRC) of Canada (C.W.B.), by a Heart and Stroke Foundation of Canada Studentship (D.R.), and by an MRC Scientist Award (C.W.B.). We thank S. H. R. Oliet, T. E. Fisher, and D. L. Voisin for their helpful criticism of an earlier version of this manuscript.

Correspondence should be addressed to Dr. Charles W. Bourque, Division of Neurology, Montréal General Hospital, 1650 Cedar Avenue, Montréal, Québec, Canada H3G 1 A4.

Copyright (C) 1996 Society for Neuroscience $0270-6474 / 96 / 167526-07 \$ 05.00 / 0$ osmotic regulation of fluid balance, the cellular basis for its role as a neuromodulator remains unknown.

Central efferent pathways mediating the perception of thirst and salt appetite remain undefined, making it difficult to study the cellular mechanisms by which such responses may be regulated by neuromodulators and neurotransmitters. The osmotic control of diuresis, however, is known to be achieved specifically through changes in the electrical activity of hypothalamic magnocellular neurosecretory cells (MNCs), which control the secretion of vasopressin from the neurohypophysis (Bourque et al., 1994). Hypothalamic MNCs, therefore, offer an ideal opportunity to examine the cellular basis underlying the modulatory actions of ANP in the CNS. Indeed, hypothalamic nuclei comprising MNCs are innervated by fibers containing ANP (Standaert et al., 1986, 1987; Saper et al., 1989), and they express binding sites for radiolabeled ANP (Gibson et al., 1986; Kurihara et al., 1987). Moreover, local application of natriuretic peptides reduces the basal electrical activity of MNCs in vivo (Standaert et al., 1987) and in vitro (Okuya and Yamashita, 1987; Yamamoto et al., 1991; Akamatsu et al., 1993; Oliet and Bourque, 1993c). The mechanism by which ANP may modulate the osmoresponsiveness of these cells, however, is unknown.

The osmotic control of MNC firing is achieved both as a result of the intrinsic osmosensitivity of these cells (Mason, 1980; Bourque, 1989; Oliet and Bourque, 1993a,b) and by changes in the frequency of spontaneous glutamatergic EPSPs they receive from osmoreceptor afferents derived from the organum vasculosum laminae terminalis (OVLT) (Richard and Bourque, 1995). In this study, therefore, we examined the modulatory effects of ANP 
on these components during intracellular recordings from MNCs in the rat supraoptic nucleus (SON).

\section{MATERIALS AND METHODS}

Preparation of explants. Basal hypothalamic explants $(8 \times 8 \times 2 \mathrm{~mm})$ were prepared as described previously (Bourque, 1990), using the brains of male Long-Evans rats (200-300 gm) killed by decapitation. The explants were pinned to the Sylgard base of a temperature-controlled $\left(32-34^{\circ} \mathrm{C}\right)$ recording chamber. The optic nerves were cut proximal to the optic chiasm to expose the OVLT, and the pial membranes overlying the SON and OVLT were removed using fine forceps. The area of the SON was superfused $(1.0 \mathrm{ml} / \mathrm{min})$ with oxygenated $\left(95 \% \mathrm{O}_{2} / 5 \% \quad \mathrm{CO}_{2}\right)$ artificial cerebrospinal fluid (ACSF; see below) delivered from a tube placed over the caudal end of the optic tract. The OVLT was superfused separately $(0.3 \mathrm{ml} / \mathrm{min})$ via a second tube placed near the rostral tip of the optic chiasm (Richard and Bourque, 1995).

Solutions. The ACSF (295 $\pm 2 \mathrm{mOsm} / \mathrm{kg}), \mathrm{pH} 7.4$, comprised (in mM): $113 \mathrm{NaCl}, 3 \mathrm{KCl}, 1.3 \mathrm{MgCl}_{2}, 25.9 \mathrm{NaHCO}_{3}, 2 \mathrm{CaCl}_{2}$, and 10 glucose. Hypertonic solutions were made by adding mannitol to the ACSF. Hypertonic stimulation of the SON was achieved by infusing hypertonic solution via a small catheter inserted into the tube superfusing this area (Bourque, 1989). Hypertonic stimulation of the OVLT was achieved by bath-application of hypertonic solutions through the main delivery tube superfusing the OVLT. The osmolality of all solutions was verified using a freezing-point micro-osmometer (VWR Scientific, West Chester, PA). ANP (rat ANP 1-28; Peninsula Laboratories, Belmont, CA), 3'-5'dibutyryl cGMP (db-cGMP; Sigma, St. Louis, MO), 6-cyano-7nitroquinoxaline-2,3, dione (CNQX; Tocris Neuramin, Bristol, UK) and D,L-2-amino-5-phosphonovalerate (APV; Sigma) were dissolved in ACSF and bath-applied over the SON. NMDA (Sigma) and AMPA (Sigma) were injected via a catheter inserted into the tube superfusing the SON.

Electrophysiology. Pipettes were prepared by pulling glass capillary tubes $(1.2 \mathrm{~mm}$ outer diameter) on a horizontal P-87 puller (Sutter Instruments, Novato, CA). The recording electrodes were filled with $2 \mathrm{M}$ potassium acetate (70-120 M $\Omega$ ) and connected to the headstage of an Axoclamp 2A amplifier (Axon Instruments, Foster City, CA) via a Ag$\mathrm{AgCl}$ wire. Each cell was impaled by advancing the microelectrode in rapid steps (4 mM) with a piezoelectric device (Burleigh, Fishers, NY). Two copies of membrane voltage, one filtered at $0-5000 \mathrm{~Hz}$ and the other at $10-1000 \mathrm{~Hz}$, were displayed on a chart recorder, digitized $(44 \mathrm{kHz}$; Neuro Data Instruments, Delaware Water Gap, PA), and stored on videotape for off-line analysis. Electrical stimulation of the OVLT was achieved using a bipolar platinum electrode $(0.3 \mathrm{~mm}$ outer diameter; $40-200 \mu \mathrm{A} ; 80-150 \mu \mathrm{sec}$ ) placed at the anteroventral midline wall of the third ventricle, dorsal to the optic chiasm. In these experiments, bicuculline methochloride (5-10 $\mu \mathrm{M}$; Tocris Neuramin) was added to the ACSF to block the GABAergic IPSP component described previously (Yang et al., 1994). Consecutive trials $(\leq 0.5 \mathrm{~Hz})$ were averaged $(n \geq 4)$ to measure the amplitude of the evoked EPSP. Input conductance $\left(G_{\text {in }}\right)$ was estimated as $G_{\text {in }}=I /\left(V_{\text {rest }}-V_{\text {ss }}\right)$, where $V_{\text {rest }}$ and $V_{\text {ss }}$ are the voltages at rest and during the steady-state phase of the electrotonic response to the application of a fixed hyperpolarizing current pulse $(I)$, respectively. Percentage change in paired-pulse facilitation $(\triangle \mathrm{PPF})$ was quantified as $\triangle P P F=100 \times\left[\left(P P F_{\mathrm{ANP}}-P P F_{\mathrm{CTR}}\right) / P P F_{\mathrm{CTR}}\right]$, where $P P F_{\mathrm{ANP}}$ and $P P F_{\mathrm{CTR}}$ are the ratioed amplitudes of the second EPSP over the first, in the presence of ANP and during control, respectively.

Spontaneous EPSP (sEPSP) analysis. The AC-coupled $(10-1000 \mathrm{~Hz})$ voltage signal was digitized $(10 \mathrm{kHz})$ using a Labmaster interface and pCLAMP software (Axon Instruments). Individual sEPSPs were detected manually using Fetchan 5.51, as described previously (Richard and Bourque, 1995). Changes in sEPSP frequency occurring in response to osmotic stimulation were analyzed by counting the number of events in 8 sec segments acquired $30 \mathrm{sec}$ immediately before and after the application of a stimulus. In five cells, the amplitudes of all manually detected sEPSPs observed during $60 \mathrm{sec}$ recording segments taken in ACSF and in the presence of ANP were measured as the difference between voltage at peak amplitude (average of 5-10 consecutive points) and baseline (average of 20-200 points preceding each event). Events were binned according to size, and cumulative probability distributions were plotted. Changes in sEPSP amplitude were assessed as shifts in the median amplitude of sEPSPs (amplitude at 0.5 probability). All data are expressed as mean \pm SEM. Statistical differences between groups were evaluated using a paired $t$ test and judged to be significant if $p<0.01$.

\section{RESULTS}

The data presented below were obtained from 36 MNCs impaled in the SON of rat hypothalamic explants. The cells displayed resting membrane potentials below $-50 \mathrm{mV}$, input resistances $>100 \mathrm{M} \Omega$, and transient outward rectification during voltage responses to depolarizing current pulses applied from holding potentials negative to $-70 \mathrm{mV}$. In addition, action potentials (amplitude $>65 \mathrm{mV}$ from baseline) evoked by depolarizing current pulses showed frequency-dependent spike broadening. Together, these features have been shown to be characteristic of rat MNCs, but not of neighboring non-neuroendocrine cells, both in vivo (Bourque and Renaud, 1991; Dyball et al., 1991) and in vitro (Bourque and Renaud, 1990).

\section{Effects of ANP on the osmotic excitation of MNCs}

The osmotic control of MNC firing is determined both by intrinsically generated changes in membrane potential (Mason, 1980; Bourque, 1989; Oliet and Bourque, 1993a,b) and by changes in the frequency of sEPSPs derived from osmoreceptor neurons in the OVLT (Richard and Bourque, 1995). We therefore examined the effects of ANP on both components. The depolarizing response of MNCs to local hypertonic stimulation $(+30 \mathrm{mOsm} / \mathrm{kg}$ ) of the SON $(5.8 \pm 0.2 \mathrm{mV})$ was not altered by bath-application of $75-150 \mathrm{~nm}$ ANP $(5.8 \pm 0.2 \mathrm{mV})$ in any of six cells tested (data not shown), indicating that the intrinsic osmosensitivity of MNCs is unaffected at these concentrations of the peptide. In contrast, bath-application of ANP (75-150 nM) over the SON consistently and reversibly abolished the excitation of MNCs that followed local hypertonic stimulation of the OVLT $(+10-20 \mathrm{mOsm} / \mathrm{kg})$ in each of five cells tested (Fig. 1). This procedure did not significantly alter either basal sEPSP frequency (Fig. $2 A$ ) or the increase in sEPSP frequency in response to hypertonic stimulation (Fig. $2 B$ ). These findings indicate that inhibition of presynaptic firing is not responsible for the blockade of OVLT-mediated responses recorded under such conditions. As illustrated in Figure 3, however, application of ANP reversibly reduced the amplitude of sEPSPs to $76 \pm 3 \%$ of control ( $p<0.01 ; n=5$; see Materials and Methods), suggesting that the inhibitory effects of ANP are mediated by a reduction in the strength of synaptic transmission between the OVLT and MNCs of the SON.

\section{Effects of ANP on EPSPs evoked by electrical stimulation of the OVLT}

In agreement with an inhibitory effect on synaptic transmission, superfusion of ANP (1.5 to $500 \mathrm{~nm}$ ) over the SON reversibly attenuated the amplitude of EPSPs evoked by electrical stimulation of the OVLT (Fig. 4A). This effect was consistently observed in each of 21 cells tested. Because vasopressin- and oxytocinreleasing MNCs occur in equal proportions in the rat SON (Vandersande and Dierickx, 1975), it can be presumed that both types of MNCs are subject to the inhibitory actions of ANP. As shown in Figure $4 B$, the effects of ANP on evoked EPSPs were dose-dependent $\left(\mathrm{IC}_{50} \sim 3 \mathrm{nM}\right)$, with maximal inhibition being observed at concentrations $\geq 30 \mathrm{~nm}$. Consistent with the intrinsic guanylate cyclase (GC) activity of receptors for ANP (Chinkers et al., 1989; Schultz et al., 1989), the effect of the peptide on evoked EPSP amplitude was mimicked by application of db-cGMP (0.5-1 $\mathrm{mm} ; n=3$ ) (Fig. $5 A$ ). In the presence of saturating concentrations of ANP, the amplitude of evoked EPSPs was attenuated by $46 \pm$ $2 \%$ (mean \pm SEM; $n=9$ ), a value that coincides with the inhibitory effects of $1 \mathrm{~mm}$ db-cGMP (46\%). As reported previously (Yang et al., 1994; Richard and Bourque, 1995), the evoked 

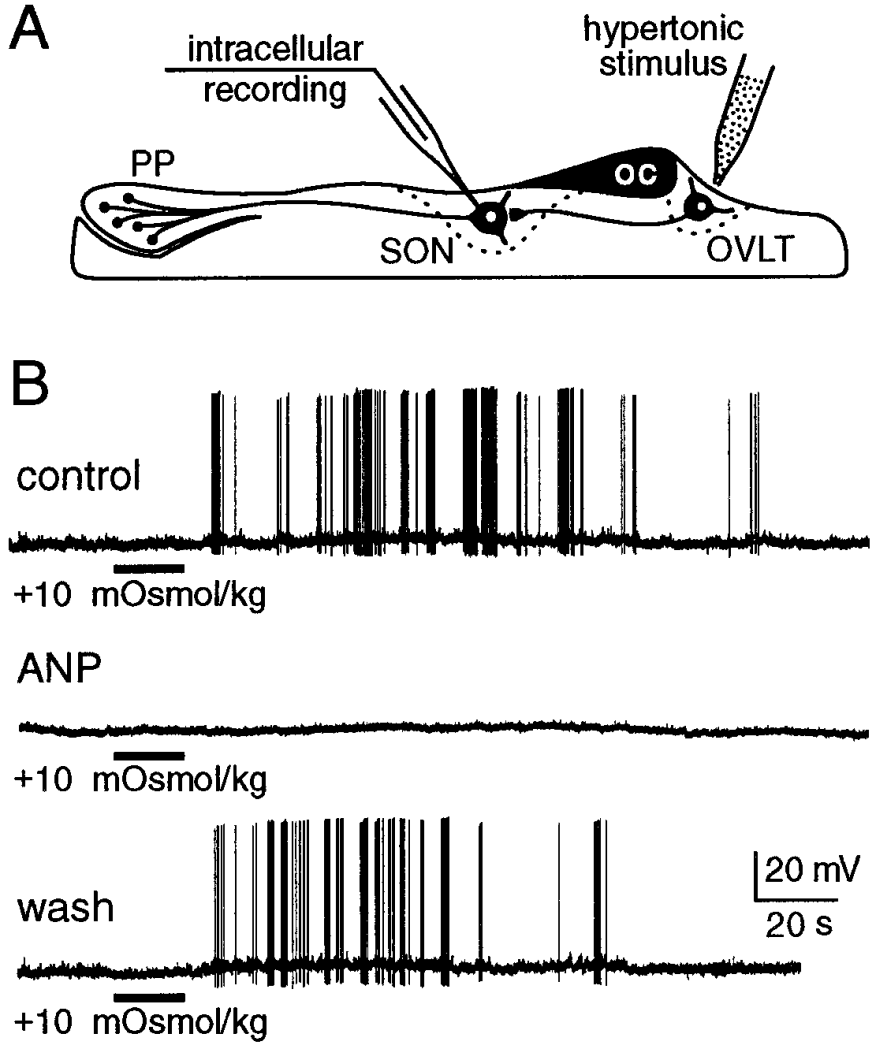

Figure 1. Effects of ANP on the osmoresponsiveness of MNCs impaled in the supraoptic nucleus $(S O N)$ of hypothalamic explants. $A$, Schematic diagram of experimental setup illustrating the relative positions of MNCs projecting to the posterior pituitary $(P P)$ and of their afferents from osmoreceptor neurons in the OVLT. OC, Optic chiasma. B, Chart recordings of voltage responses recorded in MNCs in response to hypertonic stimulation of the OVLT (bar). Bath application of $A N P(150 \mathrm{nM})$ reversibly blocked the excitatory response of the cell to the hypertonic stimulus. Initial membrane potential was $-53 \mathrm{mV}$ in each of the trials shown.

EPSPs were reversibly abolished by the application of CNQX and APV $(20-40 \mu \mathrm{M}$ each; $n=4)$ (Fig. 5B), confirming that the modulatory effects of ANP and db-cGMP are produced at glutamatergic synapses.

\section{Effects of ANP on responses to ionotropic glutamate receptor agonists}

Although the above observations demonstrate an inhibitory role for ANP on glutamatergic transmission, they do not indicate whether modulation occurs pre- or postsynaptically. The bottom panel in Figure 4 reveals that the input conductance of MNCs was unaffected by ANP under the present conditions. A postsynaptic shunting effect, therefore, did not mediate the attenuation of spontaneous and evoked EPSP amplitude observed in the presence of ANP. We next examined whether ANP could modify the postsynaptic responses of MNCs to ionotropic glutamate receptor activation. As shown in Figure 6, depolarizing responses of MNCs to exogenously applied NMDA $(20-30 \mu \mathrm{M} ; n=3)$ or AMPA (20-30 $\mu \mathrm{M} ; n=3$ ) were unaltered in the presence of the peptide (75-150 nM), indicating that the inhibitory effects of ANP are not attributable to a modulation of postsynaptic glutamate receptors.

\section{Effects of ANP on PPF}

In response to pairs of electrical stimuli delivered to the OVLT $(15-20 \mathrm{~Hz})$, the amplitude of the second EPSP evoked in MNCs

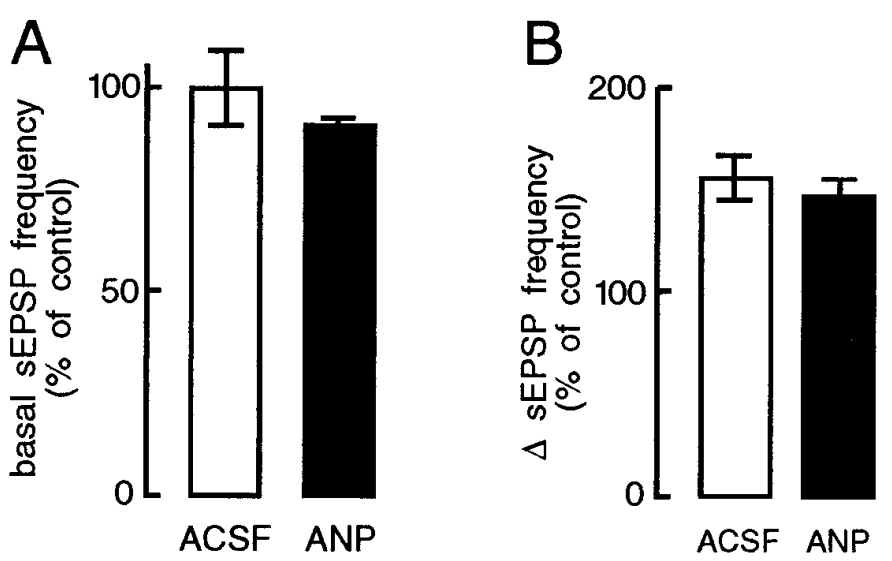

Figure 2. Effects of ANP on the frequency of sEPSPs recorded from MNCs in the SON. $A$, Bar histograms express the mean ( \pm SEM) normalized frequencies at which sEPSPs occurred in MNCs under isotonic conditions. Note that addition of ANP (75-150 nM) to the solution superfusing the SON did not significantly alter the basal frequency at which sEPSPs were detected in MNCs $(90 \pm 3 \%$ of control; $p>0.05 ; n=$ $5)$. $B$, Bar histograms express mean $( \pm \mathrm{SEM})$ normalized changes in sEPSP frequency ( $\triangle$ sEPSP frequency), relative to the basal rate (\% of control), evoked by hypertonic stimulation of the OVLT. Note that the increase in sEPSP frequency observed in ACSF (156 $\pm 12 \%$ of control) was not significantly affected by the inclusion of $75-150 \mathrm{nM}$ ANP in the solution superfusing the SON $(147 \pm 8 \% ; p>0.05 ; n=5)$.

was increased compared with the first (Fig. 7A). This phenomenon, known as PPF, has been observed at many synapses, and it reflects a selective enhancement of transmitter release (Zucker, 1989). Manipulations that decrease transmitter release enhance PPF (Mallart and Martin, 1967; Katz and Miledi, 1968). As illustrated in Figure 7, PPF of OVLT-mediated EPSPs was enhanced in the presence of ANP $(n=8)$. At a concentration of 3 $\mathrm{nM}$, which corresponds to the $\mathrm{IC}_{50}$ for ANP-mediated effects on EPSP amplitude, the mean ( \pm SEM) enhancement in PPF was $25 \pm 11 \%(n=4)$. These observations suggest that the effects of ANP on EPSPs result from a presynaptic inhibition of glutamate release.

\section{DISCUSSION}

Natriuretic peptides (Standaert et al., 1986, 1987; Saper et al., 1989) and receptors (Gibson et al., 1986; Kurihara et al., 1987) are present in hypothalamic nuclei comprising the MNCs, which release vasopressin and oxytocin into the systemic circulation (Bourque and Renaud, 1990). In the rat, intracerebroventricular injections of ANP inhibit the release of both hormones in response to rises in extracellular fluid osmolality (Itake et al., 1986; Poole et al., 1987; Samson et al., 1987; Manzanares et al., 1990). In this study, therefore, we examined the effects of ANP on the osmoresponsiveness of MNCs during intracellular recordings from rat hypothalamic explants.

\section{Inhibitory effects of ANP on the osmotic regulation of MNC firing}

The osmotic control of MNC firing is achieved through changes in an intrinsic cationic conductance (Bourque, 1989; Oliet and Bourque, 1993a,b) and by changes in the frequency of sEPSPs derived from osmoreceptor neurons within the OVLT (Richard and Bourque, 1995). Both of these components increase as a function of fluid osmolality from a threshold near $275 \mathrm{mOsm} / \mathrm{kg}$ (Bourque et al., 1994). Because this value corresponds to the osmotic pressure at which circulating neurohypophysial hormones 

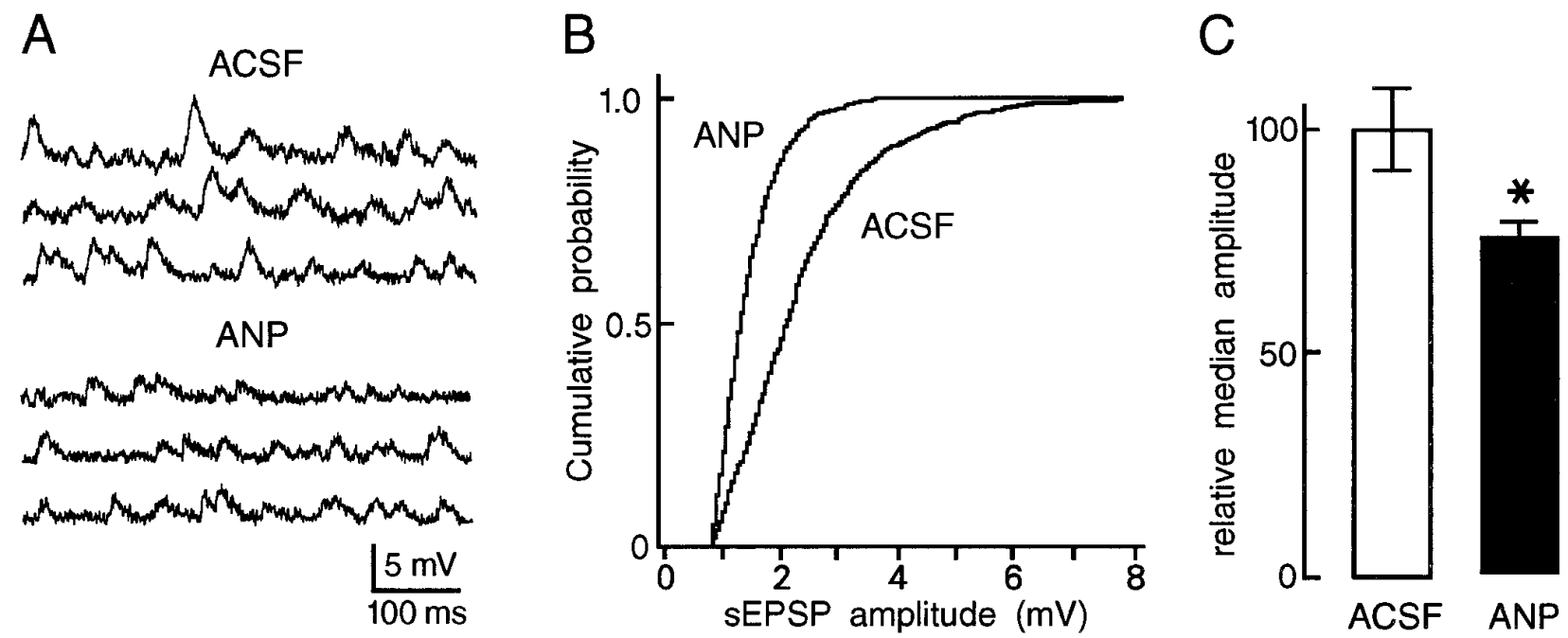

Figure 3. Effects of ANP on the amplitude of sEPSPs. $A$, High-gain voltage excerpts of a recording obtained from a rat MNC in control solution $(A C S F)$ and in the presence of $A N P(75 \mathrm{nM})$. The membrane potential was $-63 \mathrm{mV}$. $B$, The graph plots the cumulative probability distributions of sEPSP amplitude measured from a different MNC during $60 \mathrm{sec}$ recording segments obtained in ACSF ( 899 events) and in the presence of $75 \mathrm{nM}$ ANP (809 events). $C$, Bar histograms plot the mean ( \pm SEM) relative median amplitude (normalized amplitude at 0.5 probability) of the sEPSPs observed in control solutions $(A C S F ; 100 \%)$ and in the presence of $75 \mathrm{~nm} A N P$ (the asterisk denotes $p<0.01 ; n=5$ ).

become detectable by radioimmunoassay (Verbalis and Dohanics, 1991), it is likely that both processes are important for the osmotic regulation of hormone secretion in vivo. Consequently, both the intrinsic cationic conductance and the OVLT-mediated synaptic excitation represent potential targets through which centrally released ANP may modulate this process. In the present experiments, application of ANP (75-150 nM) over the SON inhibited the contribution of OVLT-derived excitatory inputs, without altering the intrinsic osmosensitivity of MNCs. Our analysis revealed that ANP does not prevent increases in the frequency of glutamatergic sEPSPs after hypertonic stimulation of the OVLT (Richard and Bourque, 1995). Rather, the inhibitory actions of the peptide are associated with an attenuation of sEPSP amplitude. These observations suggest that endogenously released ANP may impede the osmotic regulation of neurohypophysial hormone release by reducing the strength of the excitatory connection between osmoreceptor neurons in the OVLT and MNCs in the SON. In agreement with this hypothesis, applications of ANP over the SON reversibly reduced the amplitude of glutamatergic EPSPs evoked by electrical stimulation of the OVLT.

\section{The inhibitory effects of ANP are mediated by GC-A receptors}

Receptors that transduce the biological actions of natriuretic peptides feature a single membrane-spanning domain, and they possess an intrinsic GC as part of their cytoplasmic moiety. Both GC-A and GC-B have been cloned (Chinkers et al., 1989; Schultz et al., 1989), and in each case receptor activation has been shown to provoke increases in the concentration of intracellular cGMP. In our experiments, the attenuation of EPSP amplitude by ANP could be mimicked by application of db-cGMP. Furthermore, the maximal attenuation observed at saturating concentrations of ANP $(46 \%)$ coincided with the largest inhibitory effects of dbcGMP (46\% at $1 \mathrm{~mm})$. These results suggest that the inhibitory effects of ANP on supraoptic MNCs are mediated through activation of the intrinsic GC of the receptors. In agreement with this hypothesis, bath-application of ANP has been reported to cause a three- to fourfold increase in the cGMP content of tissue slices containing the SON (Akamatsu et al., 1993).
In COS-7 cells transfected with the gene encoding GC-A receptors, cGMP production resulting from exposure to ANP increases with a half-maximal concentration $\left(\mathrm{EC}_{50}\right)$ of $3 \mathrm{nM}$ (Chinkers et al., 1989; Schultz et al., 1989). In contrast, cGMP production in cells transfected with the gene coding for GC-B receptors increases as a function of ANP with an $\mathrm{EC}_{50}$ of $26 \mu \mathrm{M}$ (Schultz et al., 1989). Because inhibition of OVLT-mediated EPSPs by ANP occurred with an $\mathrm{EC}_{50}$ of $3 \mathrm{nM}$, activation of GC-A receptors presumably mediated the effects of the peptide in our experiments. Interestingly, BNP-like immunoreactivity has been detected in fibers within the SON (Saper et al., 1989), and BNP has been reported to serve as a selective agonist at GC-A receptors $\left(\mathrm{EC}_{50}=5 \mathrm{nM}\right)$ rather than at $\mathrm{GC}-\mathrm{B}$ receptors $\left(\mathrm{EC}_{50}=6 \mu \mathrm{M}\right)$ (Schultz et al., 1989). Although the effects of BNP were not examined in the present study, GC-A receptor activation by BNP, similar to that of ANP, would be expected to cause attenuation in the amplitude of OVLT-mediated EPSPs. Future studies will be needed to determine whether GC-B receptors also play a role in the regulation of MNCs.

\section{ANP causes presynaptic inhibition of glutamate release}

The fast EPSP recorded in MNCs after electrical stimulation of the OVLT results from activation of the AMPA and NMDA subtypes of ionotropic glutamate receptors (Yang et al., 1994; Richard and Bourque, 1995). It is possible, therefore, that the effects of ANP could be mediated through changes in the sensitivity or functional density of these receptors. The results presented here show that the depolarization and excitation of supraoptic MNCs induced by exogenous applications of AMPA and NMDA were unaffected by saturating concentrations of ANP (75-150 nM), suggesting that modulation of postsynaptic glutamatergic receptors does not mediate the inhibitory effects of ANP acting at GC-A receptors. Previous studies have shown that manipulations that decrease transmitter release at presynaptic terminals enhance PPF (Mallart and Martin, 1967; Katz and Miledi, 1968; Zucker, 1989). Our experiments showed that PPF of the OVLT-mediated EPSP recorded in MNCs is enhanced in the presence of ANP. Together, the observations presented here 
A
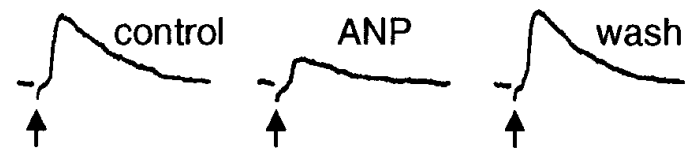

$\frac{2 \mathrm{mV}}{40 \mathrm{~ms}}$

B
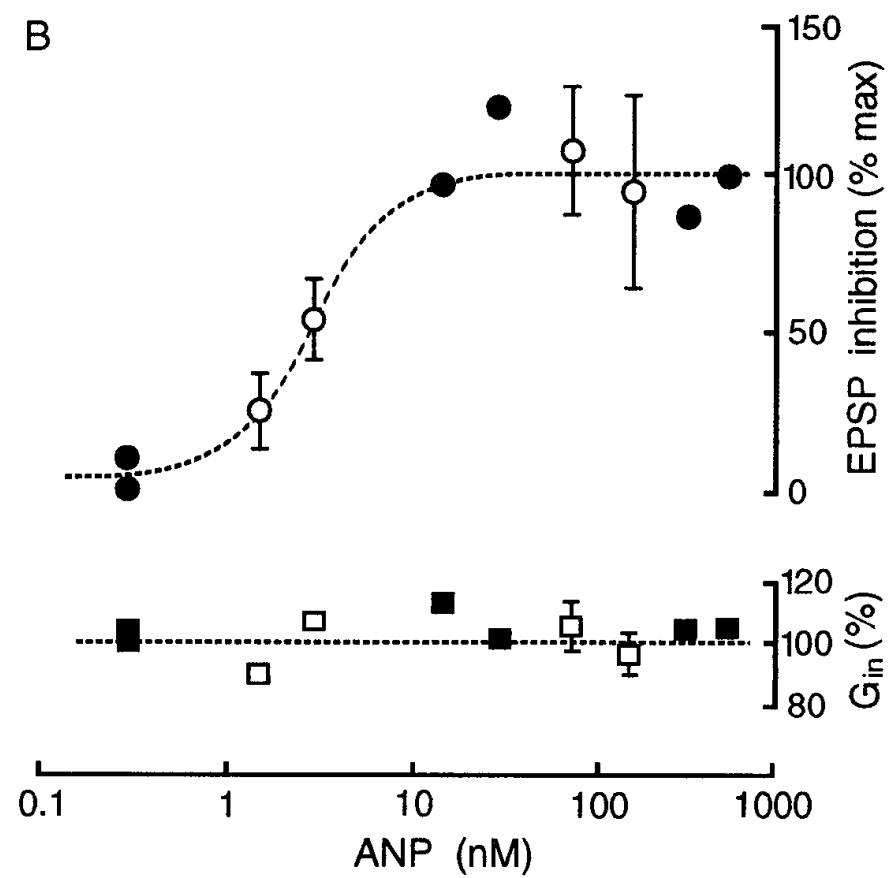

Figure 4. Effects of ANP on EPSPs evoked by electrical stimulation of the OVLT (arrows). $A$, Voltage traces showing the reversible decrease in EPSP amplitude in the presence of $A N P(75 \mathrm{nM}) . B$, The top graph plots the dose-dependency (dashed line shows $\mathrm{IC}_{50}=3 \mathrm{nM}$ ) of the effects of ANP on the relative amplitude of EPSPs evoked by OVLT stimulation. The bottom graph plots the mean input conductance $\left(G_{\text {in }}\right.$; relative to control) of cells bathed in the presence of different concentrations of ANP. Closed symbols are single measurements, whereas open symbols are mean values $\pm \mathrm{SEM} ; n \geq 3$.

suggest that ANP reduces glutamate release from axon terminals synapsing onto supraoptic MNCs.

Presynaptic effects are associated with changes in the frequency of miniature EPSPs (mEPSPs) and not with variations in mEPSP amplitude (Del Castillo and Katz, 1954). Under our experimental conditions, ANP reduced sEPSP amplitude without affecting the rate at which these were observed under basal or osmotically stimulated conditions. The majority of sEPSPs recorded in our study, however, were not mEPSPs but were synaptic events resulting from spike discharge in afferent axons. Indeed, the frequency of spontaneous synaptic events recorded in MNCs decreases dramatically on exposure to TTX (Wuarin and Dudek, 1993). Moreover, most of the sEPSPs recorded from MNCs at rest are prevented by blocking spike discharge in OVLT neurons (Richard and Bourque, 1995). Under such conditions, changes in mEPSP frequency would not be expected to have a large impact on the frequency of sEPSPs, as was observed experimentally (Fig. 2). The reduction in sEPSP amplitude induced by ANP, therefore, presumably resulted from a decrease in mean quantal content rather than from a decrease in quantal size, in agreement with a presynaptic effect.

Although the mechanisms by which ANP inhibits glutamate

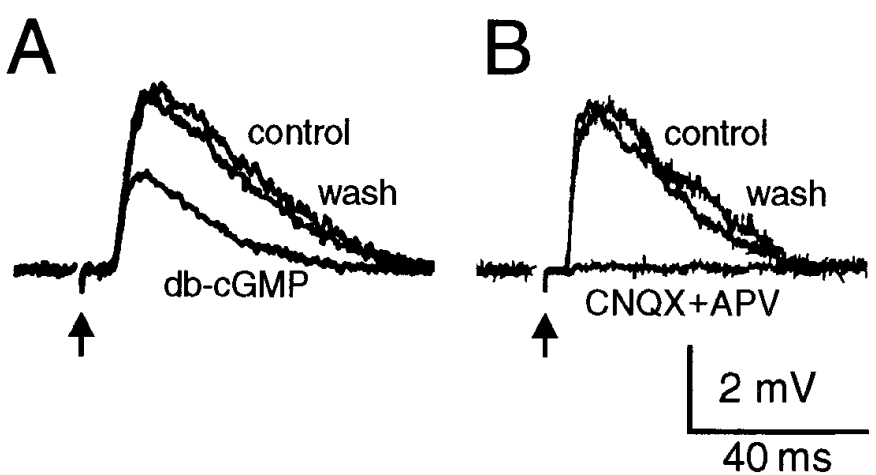

Figure 5. Effects of db-cGMP and glutamate receptor antagonists on EPSPs evoked by electrical stimulation of the OVLT (arrows). A, Superimposed traces showing the EPSP recorded from a cell before (control), during ( $d b-c G M P)$, and after (wash) bath application of $1 \mathrm{mM} \mathrm{db}$-cGMP. $B$, Superimposed traces recorded from another MNC illustrate the reversible block of the evoked EPSP by application of CNQX and APV $(25 \mu \mathrm{M}$ each).

release are unknown, the peptide reduces basal concentrations of intracellular calcium $\left(\left[\mathrm{Ca}^{2+}\right]_{\mathrm{i}}\right)$ (Hassid, 1986) and inhibits the activity of voltage-gated $\mathrm{Ca}^{2+}$ channels (Hassid, 1986; Gisbert and Fishmeister, 1988) in vascular smooth muscle and cardiac cells. The expression of either of these mechanisms in neurons could potentially result in an attenuation of the amplitude of $\left[\mathrm{Ca}^{2+}\right]_{i}$ transients occurring in response to spike discharge and reduce glutamate release from axon terminals. Moreover, a previous study in $\mathrm{GH}_{4} \mathrm{C}_{1}$ cells has shown that ANP can enhance a voltagesensitive $\mathrm{K}^{+}$conductance (White et al., 1993). By decreasing the duration of action potentials, the reduction of a repolarizing $\mathrm{K}^{+}$ current in neurons could also attenuate presynaptic $\left[\mathrm{Ca}^{2+}\right]_{\mathrm{i}}$ transients and reduce spike-evoked glutamate release. Additional studies will be required to determine which of these mechanisms, if any, underlies the inhibitory effects of ANP on glutamate release.

\section{Functional implications}

The results presented here provide a cellular mechanism for the inhibition of hypertonically evoked increases in vasopressin and oxytocin secretion by centrally administered ANP (Itake et al., 1986; Poole et al., 1987; Samson et al., 1987; Manzanares et al., 1990). As indicated earlier, the frequency of glutamatergic EPSPs derived from osmosensitive neurons within the OVLT increases in MNCs as a function of fluid osmolality, from a threshold of 275 $\mathrm{mOsm} / \mathrm{kg}$ (Richard and Bourque, 1995). Because resting osmolality in rats is near $295 \mathrm{mOsm} / \mathrm{kg}$ (Dunn et al., 1973), osmoreceptor neurons in the OVLT provide an excitatory drive to supraoptic MNCs that is tonically active at rest (Richard and Bourque, 1995). Presynaptic inhibition of this input by ANP, therefore, might be expected to reduce basal firing rate as well as increases in firing evoked by hypertonic stimulation. Although the effects of ANP on basal firing were not examined in the present experiments, previous recordings from MNCs in hypothalamic slices have revealed that in a proportion of neurons, the inhibitory effects of ANP are lost under conditions blocking synaptic transmission (Okuya and Yamashita, 1987), as would be expected for neurons in which the actions of ANP on basal firing were mediated presynaptically. Presynaptic inhibition of glutamate release from osmoreceptor afferents may underlie the effects of centrally administered ANP on other osmoregulatory mechanisms (Imura et al., 1992). 

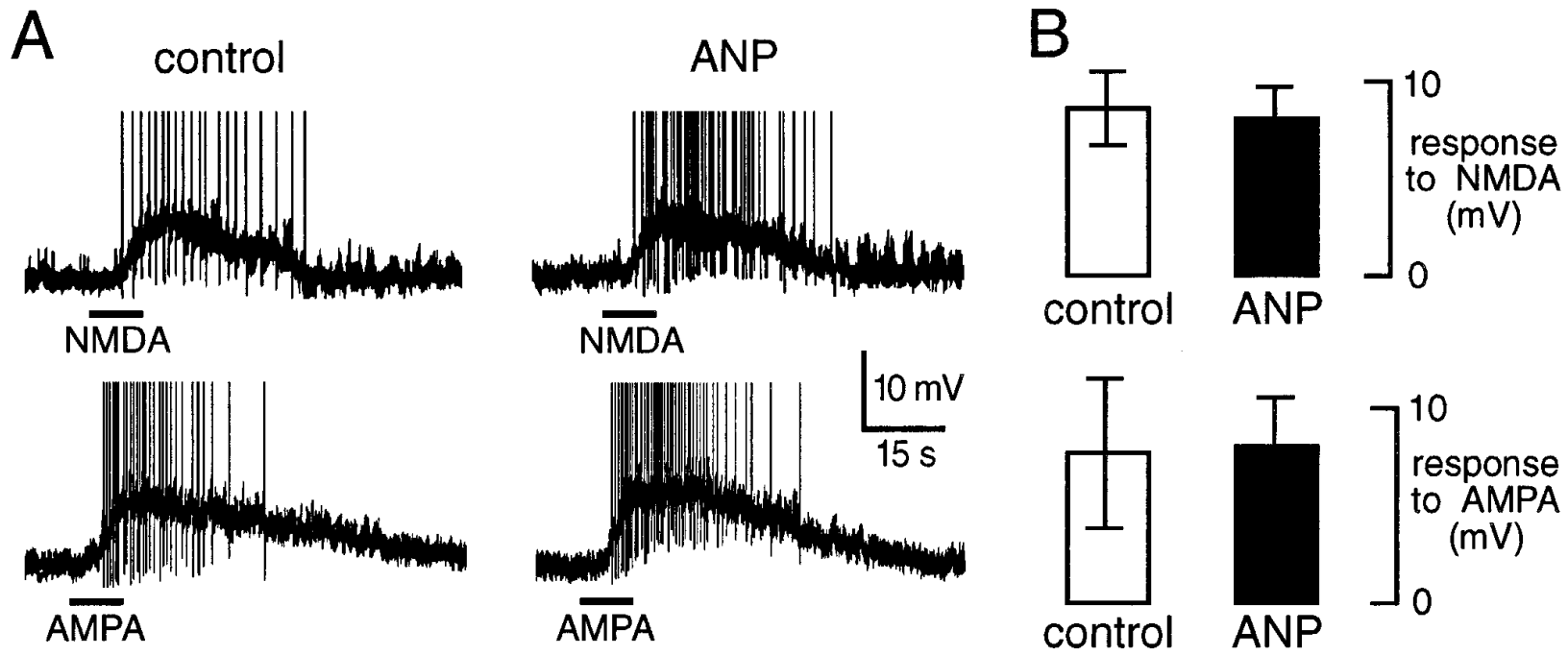

Figure 6. ANP does not affect the responsiveness of MNCs to glutamate receptor activation. $A$, Chart recordings of voltage responses from a single supraoptic MNC to applications of $25 \mu \mathrm{M} \mathrm{NMDA} \mathrm{(bars;} \mathrm{top} \mathrm{traces)} \mathrm{or} 30 \mu \mathrm{M}$ AMPA (bars; bottom traces), recorded in control solution (left panels) or in the presence of $75 \mathrm{nM}$ ANP (right panels). Initial membrane potential was $-60 \mathrm{mV}$ in each trial. Action potentials are truncated in this figure. $B$, Bar histograms plotting the mean \pm SEM amplitude of depolarizing responses to NMDA (top) and AMPA (bottom) recorded from three cells.

\section{Postsynaptic effects of ANP}

When recorded under conditions blocking synaptic transmission, a percentage of MNCs are inhibited by ANP (Okuya and Yamashita, 1987), suggesting that receptors for ANP may also be expressed postsynaptically. The existence of GC-A receptors on MNCs was demonstrated previously using whole-cell recordings from supraoptic neurons isolated from adult rats (Oliet and Bourque, 1993c). Application of 1-20 nM ANP to these cells increased a voltage-insensitive $\mathrm{K}^{+}$conductance, resulting in membrane hyperpolarization. Surprisingly, consistent effects on input conductance were not observed on application of ANP to MNCs in hypothalamic explants (Fig. 4). The lack of a postsynaptic effect in this case suggests that the target $\mathrm{K}^{+}$channels, or components of the transduction system, may be activity-dependent. Indeed, in the present study the basal firing of spontaneously active cells was suppressed by current injection to facilitate the analysis of synaptic potentials. An interesting alternative is that the postsynaptic

\section{A}

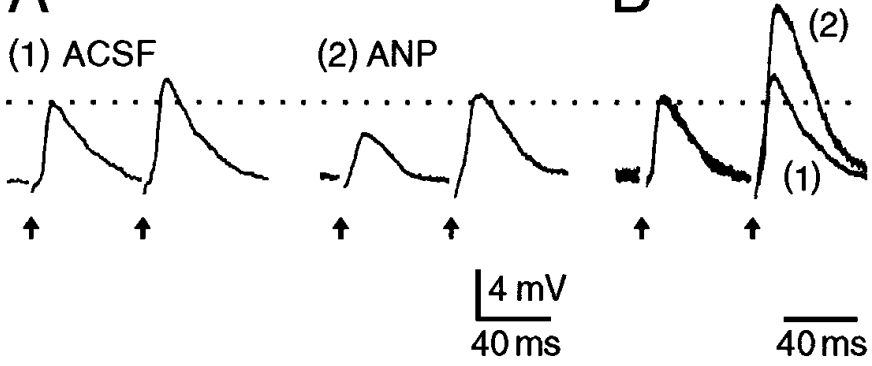

Figure 7. Inhibitory effects of ANP are presynaptic. $A$, Voltage responses of an MNC to pairs of electrical stimuli delivered to the OVLT (arrows). In $A C S F$ the amplitude of the second EPSP is enhanced relative to the first, reflecting the occurrence of PPF. The trace on the right shows the response of the same cell to identical stimuli delivered in the presence of $100 \mathrm{~nm}$ ANP. Note that the amplitude of the first EPSP recorded in ANP is attenuated compared with control but that PPF is enhanced. $B$, The traces shown in $A$ are superimposed and scaled so that the amplitudes of the first EPSPs match each other. Note the relative enhancement of the second EPSP in the presence of ANP. mechanism might be expressed differentially under different conditions. Additional studies will be required to resolve this issue.

\section{REFERENCES}

Akamatsu N, Inenaga K, Yamashita H (1993) Inhibitory effects of natriuretic peptides on vasopressin neurons mediated through cGMP and cGMP-dependent protein kinase in vitro. J Neuroendocrinol 5:517-522. Antunes-Rodrigues J, McCann SM, Rogers LC, Samson WK (1985) Atrial natriuretic factor inhibits dehydration- and angiotensin IIinduced water intake in the conscious, unrestrained rat. Proc Natl Acad Sci USA 82:8720-8723.

Antunes-Rodrigues J, McCann SM, Samson WK (1986) Central administration of atrial natriuretic factor inhibits saline preference in the rat. Endocrinology 118:1726-1728.

Bourque CW (1989) Ionic basis for the intrinsic activation of rat supraoptic neurones by hyperosmotic stimuli. J Physiol (Lond) 417:263-277.

Bourque CW (1990) The isolated and perfused mammalian hypothalamus. In: Preparations of vertebrate central nervous system in vitro (Jahnsen H, ed), pp 203-232. Chichester, UK: Wiley.

Bourque CW, Renaud LP (1990) Electrophysiology of mammalian magnocellular vasopressin and oxytocin secreting neurons. Front Neuroendocrinol 11:183-212.

Bourque CW, Renaud LP (1991) Membrane properties of rat magnocellular neuroendocrine cells in vivo. Brain Res 540:349-352.

Bourque CW, Oliet SHR, Richard D (1994) Osmoreceptors, osmoreception, and osmoregulation. Front Neuroendocrinol 15:231-274.

Brenner BM, Ballermann BJ, Gunning ME, Zeidel ML (1990) Diverse biological actions of atrial natriuretic peptide. Physiol Rev 70:665-699.

Chinkers M, Garbers DL, Chang M-S, Lowe DG, Chin H, Goeddel DV, Schultz S (1989) A membrane form of guanylate cyclase is an atrial natriuretic peptide receptor. Nature 338:78-83.

deBold AJ (1985) Atrial natriuretic factor: a hormone produced by the heart. Science 230:767-770.

Del Castillo J, Katz B (1954) Quantal components of the end-plate potential. J Physiol (Lond) 124:560-573.

Dunn FL, Brennan TJ, Nelson AE, Robertson GL (1973) The role of blood osmolality and volume in regulating vasopressin secretion in the rat. J Clin Invest 52:3212-3219.

Dyball REJ, Tasker J-G, Wuarin J-P, Dudek FE (1991) In vivo intracellular recordings of neurons in the supraoptic nucleus of the rat hypothalamus. J Neuroendocrinol 3:383-386.

Eskay R, Zukowska-Grojec Z, Haass M, Dave JR, Zamir N (1986) Circulating atrial natriuretic peptides in conscious rats: regulation of release by multiple factors. Science 232:636-639. 
Fitts DA, Thunhorst RL, Simpson JB (1985) Diuresis and reduction of salt appetite by lateral ventricular infusions of atriopeptin II. Brain Res 348:118-124.

Gibson TR, Wildey GM, Manaker S, Glembotski CC (1986) Autoradiographic localization and characterization of atrial natriuretic peptide binding sites in the rat central nervous system and adrenal gland. J Neurosci 6:2004-2011.

Gisbert MP, Fishmeister R (1988) Atrial natriuretic factor regulates the calcium current in frog isolated cardiac cells. Circ Res 62:660-667.

Hassid A (1986) Atriopeptin II decreases cytosolic free $\mathrm{Ca}$ in cultured vascular smooth muscle cells. Am J Physiol 251:C681-C686.

Imura H, Nakao K, Itoh H (1992) The natriuretic peptide system in the brain: implications in the central control of cardiovascular and neuroendocrine functions. Front Neuroendocrinol 13:217-249.

Itake K, Share L, Crofton JT, Brooks DP, Ouchi Y, Blaine EH (1986) Central atrial natriuretic factor reduces vasopressin secretion in the rat. Endocrinology 119:438-440.

Katsuura G, Nakamura M, Inoue K, Kono M, Nakao K, Imura H (1986) Regulatory role of atrial natriuretic polypeptide in water drinking in rats. Eur J Pharmacol 121:285-287.

Katz B, Miledi R (1968) The role of calcium in neuromuscular facilitation. J Physiol (Lond) 195:481-482.

Kurihara M, Saavedra JM, Shigematsu K (1987) Localization and characterization of atrial natriuretic peptide binding sites in discrete areas of rat brain and pituitary gland by quantitative autoradiography. Brain Res 408:31-39.

Lang RE, Tholken H, Ganten D, Luft FC, Ruskoaho H, Unger T (1985) Atrial natriuretic factor: a circulating hormone stimulated by volume loading. Nature 314:264-266.

Mallart A, Martin AR (1967) An analysis of facilitation of transmitter release at the neuromuscular junction of the frog. J Physiol (Lond) 193:679-694.

Manzanares J, Lookingland KJ, Moore KE (1990) Atrial natriuretic peptide-induced suppression of basal and dehydration-induced vasopressin secretion is not mediated by hypothalamic tuberohypophysial or tuberoinfundibular dopaminergic neurons. Brain Res 527:103-108.

Mason WT (1980) Supraoptic neurones of rat hypothalamus are osmosensitive. Nature 287:154-157.

Nakamura M, Katsuura G, Nakao K, Imura I (1985) Antidipsogenic action of a human atrial natriuretic polypeptide administered intracerebroventricularly in rats. Neurosci Lett 58:1-6.

Okuya S, Yamashita H (1987) Effects of atrial natriuretic polypeptide on rat hypothalamic neurones in vitro. J Physiol (Lond) 389:717-728.

Oliet SHR, Bourque CW (1993a) Steady-state osmotic modulation of cationic conductance in neurons of the rat supraoptic nucleus. Am J Physiol 265:R1475-R1479.

Oliet SHR, Bourque CW (1993b) Mechanosensitive channels transduce osmosensitivity in supraoptic neurons. Nature 364:341-343.
Oliet SHR, Bourque CW (1993c) Inhibitory effects of atrial natriuretic factor (ANF) on supraoptic neurons isolated from the rat. Soc Neurosci Abstr 19:1794.

Poole CJM, Carter DA, Vallejo M, Lightman SL (1987) Atrial natriuretic factor inhibits the stimulated in vivo and in vitro release of vasopressin and oxytocin in the rat. J Endocrinol 112:97-102.

Richard D, Bourque CW (1995) Synaptic control of rat supraoptic neurones during osmotic stimulation of the organum vasculosum lamina terminalis in vitro. J Physiol (Lond) 489.2:567-577.

Samson WK, Aguila MC, Martinovic J, Antunes-Rodrigues J, Norris M (1987) Hypothalamic action of atrial natriuretic factor to inhibit vasopressin secretion. Peptides 8:449-454.

Saper CB, Standaert DG, Currie MG, Schwartz D, Geller DM, Needleman P (1985) Atriopeptin-immunoreactive neurons in the brain: presence in cardiovascular regulatory areas. Science 227:1047-1049.

Saper CB, Hurley KM, Moga MM, Holmes HR, Adams SA, Leahy KM, Needleman P (1989) Brain natriuretic peptides: differential localization of a new family of neuropeptides. Neurosci Lett 96:29-34.

Schultz S, Singh S, Bellet RA, Singh G, Tubb DJ, Chin H, Garbers DI (1989) The primary structure of a plasma membrane guanylate cyclase demonstrates diversity within this new receptor family. Cell 58:1155-1162.

Standaert DG, Needleman P, Saper CB (1986) Organization of atriopeptin-like immunoreactive neurons in the central nervous system of the rat. J Comp Neurol 253:315-341.

Standaert DG, Cechetto DF, Needleman P, Saper CB (1987) Inhibition of the firing of vasopressin neurons by atriopeptin. Nature 329:151-153.

Vandersande F, Dierickx K (1975) Identification of the vasopressin and oxytocin producing neurons in the hypothalamic magnocellular neurosecretory system of the rat. Cell Tissue Res 164:153-162.

Verbalis JG, Dohanics J (1991) Vasopressin and oxytocin secretion in chronically hypoosmolar rat. Am J Physiol 261:R1028-R1038.

White RE, Lee AB, Shcherbatko AD, Lincoln TM, Schonbrunn A, Armstrong DL (1993) Potassium channel stimulation by natriuretic peptides through cGMP-dependent dephosphorylation. Nature 361:263-266.

Wuarin J-P, Dudek FE (1993) Patch-clamp analysis of spontaneous synaptic currents in supraoptic neuroendocrine cells of the rat hypothalamus. J Neurosci 13:2323-2331.

Yamamoto S, Inenaga K, Yamashita H (1991) Inhibition by brain natriuretic peptide of vasopressin neurons in the supraoptic nucleus and neurons in the region of the anteroventral third ventricle in rat hypothalamic slice preparations. J Neuroendocrinol 3:45-49.

Yang CR, Senatorov VV, Renaud LP (1994) Organum vasculosum lamina terminalis-evoked postsynaptic responses in rat supraoptic neurones in vitro. J Physiol (Lond) 477:59-74.

Zucker RS (1989) Short-term synaptic plasticity. Annu Rev Neurosci 12:13-31. 